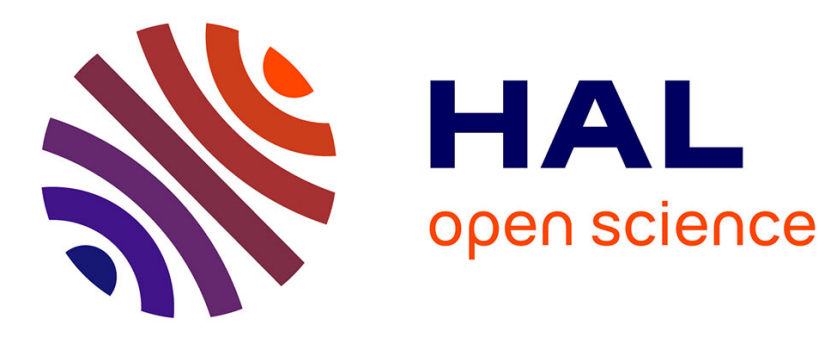

\title{
Intermittent positive-pressure breathing effects in patients with high spinal cord injury.
}

Isabelle Laffont, Djamel Bensmail, Sylvie Lortat-Jacob, Line Falaize, Claudette Hutin, Elisabeth Le Bomin, Maria Ruquet, Pierre Denys, Frédéric Lofaso

\section{To cite this version:}

Isabelle Laffont, Djamel Bensmail, Sylvie Lortat-Jacob, Line Falaize, Claudette Hutin, et al.. Intermittent positive-pressure breathing effects in patients with high spinal cord injury.: Hyperinflation in Spinal Cord Injury. Archives of Physical Medicine and Rehabilitation, 2008, 89 (8), pp.1575-9. 10.1016/j.apmr.2007.12.037 . inserm-00315866

\section{HAL Id: inserm-00315866 https://www.hal.inserm.fr/inserm-00315866}

Submitted on 1 Sep 2008

HAL is a multi-disciplinary open access archive for the deposit and dissemination of scientific research documents, whether they are published or not. The documents may come from teaching and research institutions in France or abroad, or from public or private research centers.
L'archive ouverte pluridisciplinaire HAL, est destinée au dépôt et à la diffusion de documents scientifiques de niveau recherche, publiés ou non, émanant des établissements d'enseignement et de recherche français ou étrangers, des laboratoires publics ou privés. 


\section{Intermittent Positive-Pressure Breathing Effects in \\ Patients with High Spinal Cord Injury}

Isabelle Laffont $\mathrm{MD} \mathrm{PhD}$, Djamel Bensmail MD, Sylvie Lortat-Jacob MD, Line Falaize AAS, Claudette Hutin BSc(PT), Elisabeth Le Bomin BSc(PT), Maria Ruquet AAS, Pierre Denys MD PhD, Frédéric Lofaso MD PhD

Service de Physiologie - Explorations Fonctionnelles (Falaize, Lofaso), Médecine Physique et de Réadaptation (Laffont, bensmail, Lortat-Jacob, Hutin, Le Bomin, Denys) et Centre d'Innovation Technologique (Laffont, Denys, Ruquet, Lofaso), Hôpital Raymond Poincaré, AP-HP, University of Versailles Saint Quentin en Yvelines, Garches, France Inserm UMR 841 (Lofaso), Créteil, France

Running head: Hyperinflation in Spinal Cord Injury

Correspondence: Prof. F. LOFASO

Service de Physiologie-Explorations Fonctionnelles

Hôpital Raymond Poincaré 92380 GARCHES, FRANCE

Tel: (33-1) 47107941

Fax: (33-1) 47107943

E-Mail: f.lofaso@rpc.ap-hop-paris.fr

Support: This study was supported by the Association d'Entraide des Polios et Handicapés, (ADEP) which is a non profit association.

Reprints will not be available from the authors.

ClinicalTrials gouv registration : NCT00476866 


\section{Intermittent Positive-Pressure Breathing Effects in Patients with High Spinal Cord Injury}

\section{ABSTRACT}

Objective: To determine whether intermittent positive-pressure breathing (IPPB) improved lung compliance, work of breathing, and respiratory function in patients with recent high spinal cord injury (SCI).

Design: Unblinded randomized crossover trial.

Setting: Rehabilitation hospital.

Participants: 14 patients with SCI caused by trauma within the last 6 months and located between $\mathrm{C} 5$ and $\mathrm{T} 6$.

Intervention: Two months of IPPB and two months of conventional treatment were evaluated prospectively in random order in patients with SCI.

Main outcome measures: Noninvasive lung function tests and arterial blood gas measurements were obtained repeatedly in all patients. Repeated measurements of dynamic lung compliance and work of breathing as measured by computing the area enclosed between the inspiratory esophageal pressure-tidal volume curve and the theoretical chest wall static pressure-volume curve were performed in 7 patients.

Results: IPPB had no long-term effects on vital capacity $(52.1 \pm 11.3 \% v s 54.5 \pm 12.5 \%$, after conventional treatment and IPPB respectively, $P=0.27)$, lung compliance $(66.4 \pm 48.9$ $\left.\mathrm{mL} / \mathrm{cmH}_{2} \mathrm{O} v s 70.3 \pm 38.4 \mathrm{~mL} / \mathrm{cmH}_{2} \mathrm{O}, P=0.56\right)$ and other lung function tests. Neither did IPPB exert short-term effects on lung compliance or work of breathing.

Conclusion: IPPB produced no immediate or long-term improvements in lung function or ventilatory mechanics in patients with recent SCI. 
Key Words: Paraplegia, quadriplegia, lung compliance, work of breathing, insufflation, rehabilitation. 


\section{INTRODUCTION}

Acute respiratory failure is common immediately after spinal cord injury (SCI), and pulmonary complications are the leading cause of mortality in the first year after SCI. ${ }^{1}$ Pulmonary complications have been reported to occur during the acute hospitalization in $84 \%$ of patients with $\mathrm{C} 1-\mathrm{C} 4$ injury, $60 \%$ of those with $\mathrm{C} 5-\mathrm{C} 6$ injury, and $65 \%$ of those with thoracic SCI. ${ }^{2}$ Normal or increased abdominal excursion with paradoxical inspiratory retraction of the rib cage has been noted after cervical or thoracic SCI below $\mathrm{C} 4{ }^{3,4}$ and ascribed to normal diaphragm motion contrasting with paralysis of rib-cage and abdominalwall muscles. The result of this imbalance is a reduction in lung compliance, which may develop within 1 month after SCI. ${ }^{5}$ Reduced lung compliance has also been reported in patients with kyphoscoliosis. ${ }^{6}$

In 1972, intermittent positive-pressure breathing (IPPB) for 5 minutes to induce lung hyperinflation was reported to increase lung dynamic compliance by up to $70 \%$ for up to 3 hours in patients with kyphoscoliosis. ${ }^{6}$ More than 30 years later, the same intervention was shown to induce a short-term, moderate but significant increase in lung compliance in patients with amyotrophic lateral sclerosis. ${ }^{7}$ However, an earlier study of IPPB in patients with neuromuscular disorders showed no effect on lung volumes or compliance. ${ }^{8}$ Little is known about the effects of IPPB in patients with SCI. A study of 20 minutes' IPPB in 7 patients with quadriplegia and 7 with muscular dystrophy found no improvements in ventilatory mechanics. ${ }^{9}$ However, the quadriplegics had long-standing SCI injuries, and the effect of long-term IPPB was not evaluated.

While IPPB is not a largely recognized method for the management of SCI respiratory dysfunction ${ }^{10}$, specialized Physical Medicine and Rehabilitation units of our country currently use this technique during acute care of patients with high tetraplegia. To our 
knowledge, very few complications occur with IPPB and none is described in the current literature. IPPB is usually associated with a complete respiratory rehabilitation program including techniques to enhance clearance of secretions (suctioning, manual or instrumental assisted cough), techniques to maintain thoracic flexibility (manual mobilisations), and motor reinforcement of respiratory muscles ${ }^{10}$. Binders are systematically proposed in the initial stage of rehabilitation since their efficacy is supported by other studies ${ }^{10-12}$. We hypothesized that IPPB may increase lung compliance and therefore may improve spirometry and may decrease the cost of breathing. Therefore, the objective of this study was to evaluate the immediate and 2-month effects of IPPB on lung compliance, work of breathing (WOB), and lung function in patients with recent high SCI. 


\section{METHODS}

\section{Patients}

The local ethics committee approved the study, and all patients gave their written informed consent prior to inclusion. To be included patients had to satisfy the following criteria: (a) American Spinal Injury Association (ASIA) Class A or B ${ }^{13}$ SCI caused by trauma within the last 6 months and located between $\mathrm{C} 5$ and T6, (b) no thoracic injury, (c) and admission to a rehabilitation unit. The study was conducted over the first 4 months in the rehabilitation unit.

\section{Measurements}

All tests were performed with the patients seated in their wheelchairs. Lung function was tested using a Vmax 229 Sensormedics System (Yorba Linda, CA) according to standard guidelines. ${ }^{14}$ Arterial blood gas levels were measured in capillary blood immediately after sampling from the radial artery with local anesthesia (topical lidocaine prilocaine, Emla ${ }^{\circledR}$, Astra, Westborough, ME), using a Radiometer ABL 330 analyzer (Tacussel Radiometer Analytical, Copenhagen, Denmark). Flow was measured using a Fleisch \#2 pneumotachograph (Lausanne, Switzerland) and esophageal pressure (Pes) using a cathetermounted pressure transducer system (Gaeltec, Dunvegan, UK). Appropriate placement was verified by the occlusion test. ${ }^{15}$

\section{Data Analysis}

Respiratory parameters were measured during the last 5 minutes of a 20 -minute period of relaxed breathing. From the flow tracings, we measured inspiratory time $\left(\mathrm{T}_{\mathrm{I}}\right)$ and respiratory frequency $\left(f_{R}\right)$. Tidal volume $\left(V_{T}\right)$ was obtained from the integrated flow signal. 
Dynamic lung compliance $\left(\mathrm{C}_{\mathrm{Ldyn}}\right)$ was calculated as the ratio of $\mathrm{V}_{\mathrm{T}}$ over the Pes difference at the points of zero flow corresponding to the start and end of inspiration. ${ }^{16}$ Inspiratory WOB (joule/min) was calculated from a Campbell diagram by computing the area enclosed between the inspiratory Pes- $\mathrm{V}_{\mathrm{T}}$ curve and the theoretical static pressure-volume curve of the chest wall, as previously described. ${ }^{17}$ In addition, WOB was partitioned into its elastic (WOBel) and resistive (WOBres) components on either side of the line joining the two zero-flow points.

\section{Study protocol}

All patients were studied during 2 months with and 2 months without IPPB, in random order. IPPB treatment consisted in at least 20 minutes of IPPB twice a day and 5 days a week, provided by an Alpha $200 \mathrm{C}$ ventilator (Taema, Antony, France). The patient was comfortably seated with the back of the chair inclined at $45^{\circ}$. Inspiratory pressure was increased gradually to either the highest tolerated value or $40 \mathrm{~cm} \mathrm{H}_{2} \mathrm{O}$. Respiratory rate, inspiratory flow (from 20 to $60 \mathrm{~L} / \mathrm{min}$ ), and end-inspiratory trigger were set to maximize patient comfort. The patients chose between a mouthpiece (Bird, Palm Springs, CA) and a nasal mask (Respironics, Herrsching, Germany). Few leaks around the mask may occur, however the device was always able to compensate leaks and therefore was able to reach the pressure consign when leaks were less than $1 \mathrm{~L} / \mathrm{sec}$ which was always the case. During both of the 2-month treatment periods, the number of patients who required physiotherapy to clear excess secretions and the number of physiotherapy sessions per patient were recorded.

Lung function tests were performed at inclusion and at the end of each 2-month period in all patients. In addition, patients were asked whether they agreed to measurements of flow, Pes, and gastric pressure at inclusion and at the end of each period. Measurements at the end of the IPPB period were performed twice, immediately before and immediately after 20 
minutes of IPPB with the catheter-mounted pressure-transducer system still in place. Each measurement period lasted about 5 minutes.

\section{STATISTICS}

All data are given as means \pm SD. Paired $t$ tests were used for within-patient comparisons of variables between the two treatments. Unpaired $t$ tests were used for group comparisons.

\section{RESULTS}

We included 14 patients, whose individual data are summarized in Table 1. Patients \#1 to \#7 accepted repeated transdiaphragmatic and Pes measurements.

In order to evaluate the effect of time irrespective of the treatment, we compared data obtained at the end of 2 months (end of the first treatment period) and at the end of 4 months (end of the study) in the rehabilitation unit, and observed that only vital capacity (VC) was significantly different $(50.2 \% \pm 12.5$ vs. $56.5 \% \pm 10.4, P=0.002, t$-test $)$, while IPPB had no long-term effects on vital capacity $(52.1 \pm 11.3 \% v s 54.5 \pm 12.5 \%$, after conventional treatment and IPPB respectively, $P=0.27, t$-test). VC changes in individual patients are shown in Figure 1. The means \pm SD parameters during baseline, after conventional treatment and after IPPB, are presented in Table 2. No significant differences were found in the effects of the two periods (with and without IPPB) on lung function parameters, breathing pattern, or the respiratory system mechanic. In addition the 6 patients who used IPPB during the 2 first months were not different from the remaining patients for any respiratory parameter and at any period (baseline, 2 months, 4 months) (unpaired $t$-test). 
During both treatment periods, 3 patients required physiotherapy to clear excess secretions. The number of physiotherapy sessions was not significantly different between the two periods (with IPPB: $7.2 \pm 16.3$; and without IPPB: 7.5 \pm 13.7 ). Comparisons of measurement results immediately before and immediately after 20 minutes of IPPB at the end of the 2-month IPPB period showed no significant differences in lung compliance, WOBel, or WOBres (Figure 2)

\section{DISCUSSION}

Although all our patients with SCI had low VC values at inclusion, IPPB produced neither long-term changes in lung volumes nor short- or long-term changes in lung compliance or WOB

The lung compliance decrease associated with respiratory muscle dysfunction may be ascribable to microatelectasis, increased alveolar surface tension, and/or increased lung-tissue stiffness. ${ }^{7}$ Lung compliance was better in patients with long-standing compared to recent quadriplegia, ${ }^{5}$ suggesting that lung compliance may improve over time in patients with SCI. This improvement is usually ascribed to the development of spasticity of rib-cage and abdominal muscles over time, ${ }^{3}$ which may increase the activity, and therefore the strength, of muscles that remain under voluntary control such as the cervical accessory muscles. In keeping with this hypothesis, the paradoxical rib-cage motion usually present at the acute phase of SCI decreases over time. ${ }^{5}$ Improved strength of accessory respiratory muscles may lead to greater lung expansion and, therefore, to increased lung compliance. Should this be the case, lung hyperinflation using IPPB might accelerate the spontaneous improvement in lung compliance over time.

In earlier studies, IPPB increased lung compliance and reduced WOB for up to 3 hours in patients with kyphoscoliosis ${ }^{6}$ or amyotrophic lateral sclerosis. ${ }^{7}$ In patients with SCI of at 
least 1 year's duration, in contrast, IPPB produced no significant short-term effects on chest wall or lung compliance. ${ }^{9}$ This result raised the possibility that IPPB might be beneficial when used during the first few months after SCI. Interestingly, VC improved immediately after IPPB in patients with acute quadriparesis; ${ }^{18}$ however, the mean increase was only $43 \mathrm{ml}$, which was statistically significant but considered clinically irrelevant by the authors. In keeping with earlier studies, we found no significant immediate effect of IPPB on dynamic lung compliance or WOB within 1 year of high SCI. Neither did 2 months of IPPB influence VC, lung compliance, or WOB.

\section{Limitations of the study}

We did not study the effects of IPPB on total respiratory system compliance or chest wall compliance. Unfortunately there is no information in the literature about chest wall compliance of SCI patients. To compute WOBel, we used a theoretical chest wall compliance value corresponding to a normal individual. In an earlier study involving chest wall compliance measurements, IPPB had no immediate effect on this parameter. ${ }^{9}$ A long-term effect of IPPB on the rib cage might be masked by the gradual development of rib-cage muscle spasticity. The development of spasticity may also explain the small but significant VC improvement over time seen in our patients. In keeping with this possibility, no specific respiratory-system rehabilitation techniques were used in addition to IPPB, and respiratorymuscle performance did not change concomitantly with the VC increase.

Although our pilot study should be viewed with caution given the relatively small number of patients, it suggests that routine IPPB in patients admitted to rehabilitation units for high SCI may produce small benefits at best.

IPPB is offered to patients in most SCI units, including ours. ${ }^{1}$ However, most of our patients report that the IPPB sessions are unpleasant. In addition, IPPB is costly method in terms of equipment and staff time. Respiratory muscle training has improved several 
respiratory parameters in controlled studies. ${ }^{19,20}$ Respiratory muscle training may be better than IPPB in patients with recent SCI who are free of acute respiratory complications such as excessive lung secretion and severe atelectasis, for which IPPB seems effective. ${ }^{21} \mathrm{~A}$ controlled study evaluated progressive expiratory resistive loading in order to obtain an expiratory pressure of about $60 \%$ of the maximal expiratory pressure during at least 5 minutes, 5 times a day, 6 days a week, for 8 weeks. ${ }^{20} \mathrm{VC}$ and expiratory muscle strength showed larger improvements in the trained group. Strenuous isometric training of the pectoralis major muscle significantly increased expiratory muscle strength and significantly decreased residual volume compared to controls. ${ }^{19}$. In contrast, no benefits were documented in controlled studies of interventions involving inspiratory muscle training and improved respiratory muscle endurance. ${ }^{22,23}$

In conclusion, IPPB produced no detectable short- or long-term improvements in respiratory function, lung compliance, or WOB in patients with recent SCI and without acute respiratory failure. Given the high cost and patient discomfort associated with IPPB, it should be limited as a technique among others to enhance clearance of secretions when respiratory tract infection occur, and attention should turn to muscle training methods, which have been found effective in patients with SCI. Further studies including SCI patients with acute respiratory failure are needed in order to give clear recommendations about the interest of IPPB for this acute situation. 


\section{References}

1. Wuermser LA, Ho CH, Chiodo AE, Priebe MM, Kirshblum SC, Scelza WM. Spinal cord injury medicine. 2. Acute care management of traumatic and nontraumatic injury. Arch Phys Med Rehabil 2007;88(3 Suppl 1):S55-61.

2. Jackson $\mathrm{AB}$, Groomes $\mathrm{TE}$. Incidence of respiratory complications following spinal cord injury. Arch Phys Med Rehabil 1994;75(3):270-5.

3. Bergofsky EH. Mechanism for Respiratory Insufficiency after Cervical Cord Injury; a Source of Alveolar Hypoventilation. Ann Intern Med 1964;61:435-47.

4. De Troyer A, Estenne M. Chest wall motion in paraplegic subjects. Am Rev Respir Dis 1990;141(2):332-6.

5. Scanlon PD, Loring SH, Pichurko BM, McCool FD, Slutsky AS, Sarkarati M et al. Respiratory mechanics in acute quadriplegia. Lung and chest wall compliance and dimensional changes during respiratory maneuvers. Am Rev Respir Dis 1989;139(3):615-20.

6. Sinha R, Bergofsky EH. Prolonged alteration of lung mechanics in kyphoscoliosis by positive pressure hyperinflation. Am Rev Respir Dis 1972;106(1):47-57.

7. Lechtzin N, Shade D, Clawson L, Wiener CM. Supramaximal inflation improves lung compliance in subjects with amyotrophic lateral sclerosis. Chest 2006;129(5):1322-9.

8. De Troyer A, Deisser P. The effects of intermittent positive pressure breathing on patients with respiratory muscle weakness. Am Rev Respir Dis 1981;124(2):132-7.

9. McCool FD, Mayewski RF, Shayne DS, Gibson CJ, Griggs RC, Hyde RW. Intermittent positive pressure breathing in patients with respiratory muscle weakness. Alterations in total respiratory system compliance. Chest 1986;90(4):546-52.

10. Brown R, DiMarco AF, Hoit JD, Garshick E. Respiratory dysfunction and management in spinal cord injury. Respir Care 2006;51(8):853-68; discussion 69-70.

11. Hart N, Laffont I, de la Sota AP, Lejaille M, Macadou G, Polkey MI et al. Respiratory effects of combined truncal and abdominal support in patients with spinal cord injury. Arch Phys Med Rehabil 2005;86(7):1447-51.

12. Maloney FP. Pulmonary function in quadriplegia: effects of a corset. Arch Phys Med Rehabil 1979;60(6):261-5.

13. Clinical assessment after acute cervical spinal cord injury. Neurosurgery 2002;50(3 Supp1):S21-9.

14. Quanjer PH, Tammeling GJ, Cotes JE, Pedersen OF, Peslin R, Yernault JC. Lung volumes and forced ventilatory flows. Report Working Party Standardization of Lung Function Tests, European Community for Steel and Coal. Official Statement of the European Respiratory Society. Eur Respir J Suppl 1993;16:5-40.

15. Baydur A, Behrakis PK, Zin WA, Jaeger M, Milic-Emili J. A simple method for assessing the validity of the esophageal balloon technique. Am Rev Respir Dis $1982 ; 126(5): 788-91$.

16. Mead J, Whittenberger J. Physical properties of the human lung measured during spontaneous respiration. 1953;5:779-96.

17. Lofaso F, Brochard L, Touchard D, Hang T, Harf A, Isabey D. Evaluation of carbon dioxide rebreathing during pressure support ventilation with airway management system (BiPAP) devices. Chest 1995;108(3):772-8.

18. Stiller K, Simionato R, Rice K, Hall B. The effect of intermittent positive pressure breathing on lung volumes in acute quadriparesis. Paraplegia 1992;30(2):121-6.

19. Estenne M, Knoop C, Vanvaerenbergh J, Heilporn A, De Troyer A. The effect of pectoralis muscle training in tetraplegic subjects. Am Rev Respir Dis 1989;139(5):1218-22.

20. Gounden P. Progressive resistive loading on accessory expiratory muscle in tetraplegia. South african Journal of Physiotherapy 1990:4-15. 
21. Denehy L, Berney S. The use of positive pressure devices by physiotherapists. Eur Respir J 2001;17(4):821-9.

22. Liaw MY, Lin MC, Cheng PT, Wong MK, Tang FT. Resistive inspiratory muscle training: its effectiveness in patients with acute complete cervical cord injury. Arch Phys Med Rehabil 2000;81(6):752-6.

23. Loveridge $B$, Badour $M$, Dubo $H$. Ventilatory muscle endurance training in quadriplegia: effects on breathing pattern. Paraplegia 1989;27(5):329-39. 


\section{Figure legends}

\section{Figure 1}

Changes in vital capacity (VC) over time in individual patients. The dotted lines and open circles indicate periods with intermittent positive-pressure breathing (IPPB) and the solid lines and closed circles the periods without IPPB.

\section{Figure 2}

Dynamic lung compliance and inspiratory elastic and resistive work of breathing (WOB) immediately before and after 20 minutes of hyperinflation using intermittent positive-pressure breathing (IPPB). 